\title{
Challenges in breast cancer management and prevention
}

\author{
Manuel Debald ${ }^{1,2}$, Walther Kuhn ${ }^{1,2}$, Olga Golubnitschaja ${ }^{2,3^{*}}$ \\ From EPMA-World Congress 2013 \\ Brussels, Belgium. 20-21 September 2013
}

Breast cancer is the most frequently diagnosed cancer entity and the leading cause of cancer death in females worldwide, accounting for $23 \%$ of the total new cancer cases and $14 \%$ of the total cancer deaths in 2008 [1]. Recently, prophylactic mastectomy in patients with family history for breast cancer or patients with BRCA1 or BRCA2 mutations became a widely discussed topic due to the wide media presence of celebrities undergoing this procedure. Prophylactic mastectomy in patients with BRCA 1/2 mutations reduces the risk for breast cancer by approximately $90 \%$. Nevertheless, young patients undergoing this risk reducing surgery carry many fears and psychological stress by feeling less female and are faced by a life-changing decision. In addition, several studies demonstrated that not all patients with a breast cancer history do really benefit from prophylactic surgery of the contralateral breast that trigger controversial discussions regarding optimized breast cancer management [2].

Economic burden of breast cancer management are permanently increasing negatively impacting the healthcare budgets. In the actual context of extensive debates concerning increasing costs of medical services and limited resources to cover healthcare costs, new strategies needs to be applied to more effective breast cancer management. To give an example, in the USA the costs for prescriptions against breast cancer are the second largest category of all pharmaceutical sales with enormously increasing rates. The therapy costs for each patient with metastatic breast cancer have been reported to be $\$ 128.556$ over a mean follow-up time of 18 month. But also the trend towards the detection of earlier breast cancer stages is under discussion regarding treatment savings. The savings of costs for treatment

\footnotetext{
* Correspondence: olga.golubnitschaja@ukb.uni-bonn.de

${ }^{2}$ Breast Cancer Research Centre, University of Bonn, Germany

Full list of author information is available at the end of the article
}

and palliative care in advanced breast cancer may be counterbalanced by the high costs of more aggressive initial treatments and longer follow-up.

Currently applied screening strategies lack sufficient benefits and, therefore, also become disputed. The diagnosis of breast cancer in early stages has been shown to improve the prognosis and consecutively reduce mortality of breast cancer patients. The recommended screening by clinical breast examination and mammography is able to detect breast cancer in early stages and has been shown to reduce mortality. Nevertheless, this screening procedures cause high percentages of false-negative and false-positive results that lead to both underdiagnosis and overdiagnosis respectively [3]. Furthermore, established mammography screening programs are restricted to certain age-groups (50-69 years) and specialized screening units and not feasible in most economically developing countries.

\section{Recommendations}

Based on the enormous amount of health care costs for breast cancer screening, therapy costs as well as the economic burden of this disease, predictive medicine could be an innovative approach towards a new era in breast cancer prevention. Breast cancer risk assessment aims at detection of pre-malignant stages that will revolutionise breast cancer management in patients without family history as well as in women with hereditary disease. Innovative approaches proposed by the PPPM paradigm promote economically more attractive scenario for the investment in healthcare sector, however, should get carefully analysed through well designed pilot projects $[4,5]$.

\section{Authors' details \\ 'Department of Obstetrics and Gynaecology, Centre for Integrated Oncology, University of Bonn, Germany. ${ }^{2}$ Breast Cancer Research Centre, University of Bonn, Germany. ${ }^{3}$ Department of Radiology, Rheinische Friedrich-Wilhelms-University of Bonn, Sigmund-Freud-Str. 25, Germany.}




\section{Published: 11 February 2014}

\section{References}

1. Jemal A, Bray F, Center MM, Ferlay J, Ward E, Forman D: Global cancer statistics. CA Cancer J Clin 2011, 61:69-90.

2. Brewster AM, Bedrosian I, Parker PA, Dong W, Peterson SK, Cantor SB, Crosby M, Shen Y: Association between contralateral prophylactic mastectomy and breast cancer outcomes by hormone receptor status. Cancer 2012, 118:5637-5643.

3. Jorgensen KJ, Gotzsche PC: Overdiagnosis in publicly organised mammography screening programmes: systematic review of incidence trends. BMJ 2009, 339:b2587.

4. Golubnitschaja O, Yeghiazaryan K, Costigliola V, Trog D, Braun M, Debald M, Kuhn W, Schild HH: Risk assessment, disease prevention and personalised treatments in breast cancer: is clinically qualified integrative approach in the horizon? EPMA J 2013, 4:6.

5. Debald M, Yeghiazaryan K, Cebioglu M, Kuhn W, Schild HH

Golubnitschaja O: "Suspect molecular signature" in blood as the indicator for undiagnosed breast cancer, cancer risk and targeted prevention. EPMA J 2013, 4(22).

doi:10.1186/1878-5085-5-S1-A41

Cite this article as: Debald et al: Challenges in breast cancer management and prevention. EPMA Journal 2014 5(Suppl 1):A41.

\section{Submit your next manuscript to BioMed Central} and take full advantage of:

- Convenient online submission

- Thorough peer review

- No space constraints or color figure charges

- Immediate publication on acceptance

- Inclusion in PubMed, CAS, Scopus and Google Scholar

- Research which is freely available for redistribution

Submit your manuscript at www.biomedcentral.com/submit 